\title{
Prediction of Slag Pool Thickness in Continuous Casting Mould
}

\author{
N. PRADHAN, M. GHOSH, ${ }^{1)}$ D. S. BASU and S. MAZUMDAR ${ }^{2)}$
}

Casting Group, Research and Development Centre for Iron \& Steel, Steel Authority of India Limited, P.O.-Doranda, Ranchi-834002, (Bihar) India. $\quad 1$ ) M\&S Laboratory, Research and Development Centre for Iron \& Steel, Steel Authority of India Limited, P.O.-Doranda, Ranchi-834002, (Bihar) India. $\quad 2)$ AS \& C Division, Research and Development Centre for Iron \& Steel, Steel Authority of India Limited, P.O.-Doranda, Ranchi-834002, (Bihar) India.

(Received on March 1. 1998; accepted in final form on May 12, 1999)

Physical properties of mould powder control the surface equality of the continuously cast products. Formation of mould slag of specific quality in caster mould requires correct formulation of melting rate property so that molten slag of adequate thickness is continuously generated. The melting of the casting powder, apart from mineralogical composition, is influenced by caster application conditions such as casting speed, oscillation parameters etc. The known melting rate tests are not amenable for quantitative prediction of slag pool thickness since they do not consider all the application conditions together.

Present work describes a methodology predicting slag pool thickness based on melting rate measurements using various known experimental techniques. The measured melting rate data has been combined to generate acceleration coefficients incorporating effect of slag consumption and mould oscillation on powder melting. An effective melting rate parameter (EMR) has been formulated using these coefficients. Measured slag pool thickness $(d)$ during actual casting correlates well with the defined EMR in the speed range of 0.55 to $1.5 \mathrm{~m} / \mathrm{min}$.

$$
d=35.70 \cdot \mathrm{EMR} \cdot \mathrm{V} /(a \cdot b)+2.1, \quad R^{2}=0.94
$$

The high confidence level of this correlation indicates applicability of effective melting rate parameter (EMR) concept for prediction of slag pool thickness.

KEY WORDS: mould powder; casting powder; melting rate; slag pool thickness.

\section{Introduction}

The performance of casters is strongly influenced by properties of mould powder in regard to lubrication, heat transfer and the surface quality of the continuous cast product. ${ }^{1-3)}$ The physical properties of powder such as viscosity, solidification and crystallization temperature etc. are critically important for achieving desired caster performance with respect to the steel grade being cast. ${ }^{4-5)}$ But these properties can only be realised during continuous casting when the powder is fully molten and forms required amount of slag pool. ${ }^{6}$ )

A minimum slag pool thickness is necessary in order to:

- Ensure continuous supply of slag into mould-strand gap during down stroke (negative strip). ${ }^{7-8)}$ Consequently slag pool thickness ought to be more than stroke length. ${ }^{9)}$

- Avoid balding of meniscus-thus entrapment. ${ }^{10)}$

- Avoid carbon pick-up from mould powder. ${ }^{11)}$

Excess pool thickness, on the other hand, is considered detrimental on account of:

- Excessive slag rim formation leading to stoppage of slag supply into mould strand gap. ${ }^{2,9)}$

- Partial solidification of the molten steel surface. ${ }^{2)}$

The melting behavior of the powder which determines extent of molten slag pool formation ${ }^{2.6,12)}$ has not been characterised satisfactorily. The known melting rate tests are empirical in nature and is not directly amenable to quantitative prediction of slag pool thickness during actual casting. Difficulty arises due to effect of caster application conditions on powder melting e.g. mould oscillation, casting speed and section size of the caster. ${ }^{6,13,14)}$

The melting rate tests devised only partly simulates the application conditions. The vitrification test developed by Koyama et al. ${ }^{13)}$ simulates only unidirectional heat flow. The melting rate procedure of Xie et al. ${ }^{15)}$ additionally takes into account slag melting under draining condition. Similarly oscillation effect is accounted for in the study by Nakano et al. ${ }^{14)}$

Two types of approach were reported in literature for quantitative prediction of slag pool thickness in continuous casting mould e.g. mathematical modeling ${ }^{14.17)}$ or empirical correlations using experimental data. ${ }^{13}$ The former, however, is quite preliminary in nature and would require major modification for utilisation in predictive mode.

Koyama et $a l .{ }^{13)}$ attempted an empirical approach for predicting pool thickness using vitrification test developed by themselves. The correlation developed was: 


$$
d \propto \frac{S_{\mathrm{R}}}{a \cdot b}
$$

Where, $\quad d=$ Slag pool thickness

$a \cdot b=$ Section size of the cast

$S_{\mathrm{R}}=$ Melting rate determined through vitrification test

The proportionality constant of the above equation was determined using plant based measurements and was supposed to encompass various accelerating factors of melting rate due to application conditions. The predictive capability was of the order of only $\pm 50 \%$. Despite inadequacy of prediction, this work establishes that slag pool thickness is directly proportional to melting rate of the powder and inversely proportional to the cross sectional area of the mould. Nevertheless, dependence of Koyama's method on plant test severely limits applicability of the approach for predictive purposes.

Qualitatively, similar effect as Koyama et al. ${ }^{13)}$ has been reported by Mills. ${ }^{6)} \mathrm{He}$ observed that slag pool thickness increases with increase in melting rate of the powder, decrease of mould dimension and increase of casting speed. Similar effect of casting speed was also reported by Riboud. ${ }^{16)}$

The above studies indicate applicability of correlation of the type given in Eq. (2) for prediction of slag pool thickness.

$$
d \propto \frac{\text { Melting rate } \times \text { casting speed }}{\text { Section size of caster }}
$$

The melting rate proposed in Eq. (2) ought to incorporate effect of major application condition, i.e. the effect of mould oscillation and slag drainage.

Present work attempts to define effect of application conditions on melting rate by integrating melting rate results generated through diverse experimental techniques. Applicability of the approach along with correlations developed have been demonstrated for a limited range of powder type using free carbon (graphite) as inhibitor in the range typical of slab casting.

\section{Experimental}

The melting rate measurements utilised in the present work are known methods reported in the literature. For comparability of results from various tests, melting rate data were converted into common unit i.e. $\mathrm{g} / \mathrm{cm}^{2} / \mathrm{min}$.

\subsection{Melting Rate Measurement under one Directional Heating, (MR)}

The set up for melting rate measurement for unidirectional heating condition is shown in Fig. 1. ${ }^{13)} \mathrm{A}$ fixed amount of powder was placed in a carbon crucible kept on graphite block and heated through induction furnace. The temperature of the crucible was maintained at $1773 \pm 5 \mathrm{~K}$. The crucible was taken out for slag separation after $7 \mathrm{~min}$ of heating. The amount of slag melted per unit time $(\mathrm{min})$ per unit area $\left(\mathrm{cm}^{2}\right)$ is taken as melting rate under one directional heating. Experimental time of 7 min was taken based on calculation ${ }^{18}$ )

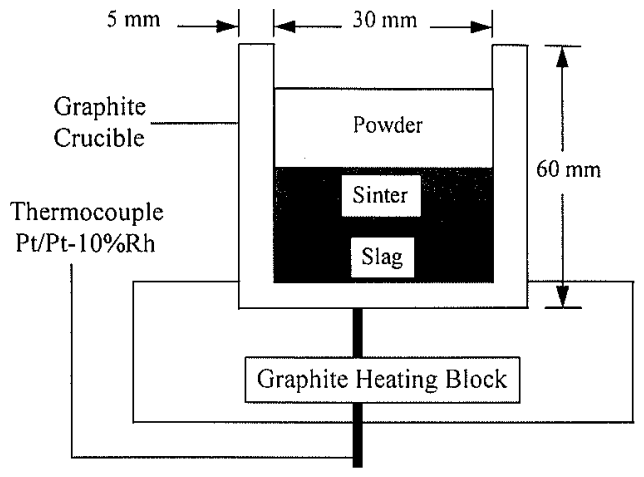

Fig. 1. Set up for melting rate measurement under one directional heating.
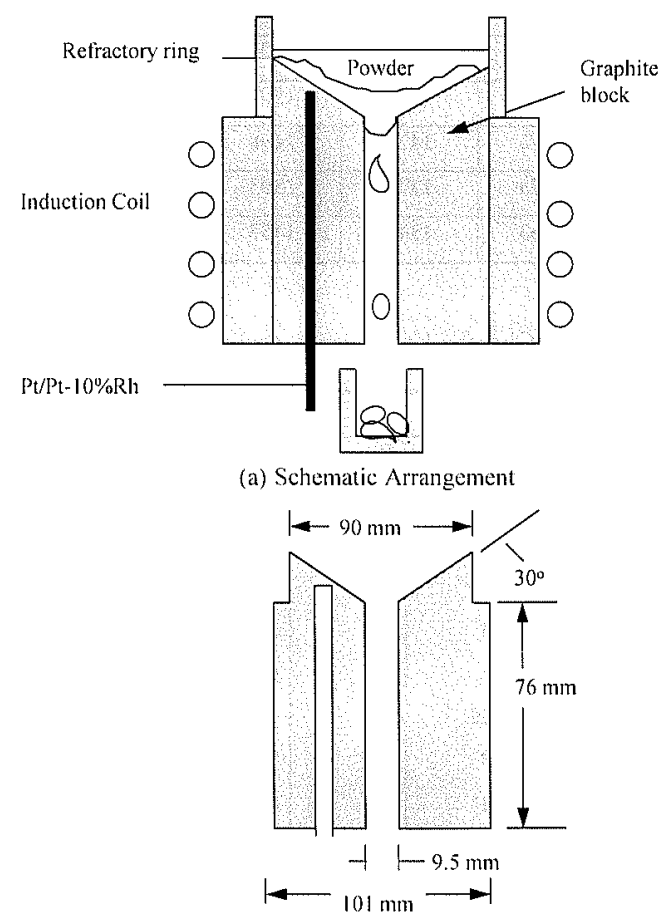

(b) Dimension of graphite block

Fig. 2. Apparatus for melting rate measurement under slag drainage condition.

of slag decent time in the mould from top of the powder layer to meniscus.

\subsection{Melting Rate Measurement under Draining Condi- tion, $(\mathrm{MR})_{\mathrm{d}}$}

The set up for melting rate measurement for one directional heating under slag drainage facilities is shown in Figs. 2(a) and 2(b). ${ }^{15)}$ Powder was kept in a carbon heating block having inclined walls with a central hole. The temperature of the graphite block was maintained as $1773 \pm 5 \mathrm{~K}$ and a fixed quantity of powder was added. The amount of slag collected in $7 \mathrm{~min}$ was taken as melting rate for the powder $\left(\mathrm{g} / \mathrm{cm}^{2} / \mathrm{min}\right)$.

\subsection{Melting under Oscillation}

The experimental rig used for melting rate measurement under oscillation is shown in Fig. . $^{14)}$ The oscillator was capable to oscillate at a frequency range of $0-200$ cycle per minute. The stroke length of the oscillator was kept at $6 \mathrm{~mm}$. A refractory annular ring was fitted to the 


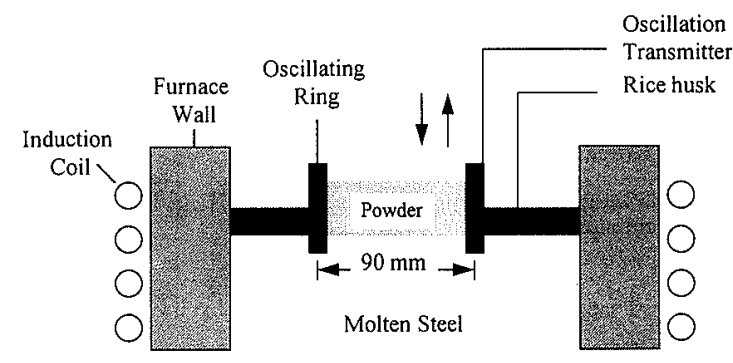

Fig. 3. Schematic arrangement for melting rate measurement under oscillation.

Table 1(a). Physical properties of test mould powder.

\begin{tabular}{|c|c|c|c|c|}
\hline $\begin{array}{l}\text { Powder } \\
\text { type }\end{array}$ & $\begin{array}{l}\text { Fusion } \\
\text { point } \mathbf{K}\end{array}$ & $\begin{array}{l}\text { Melting } \\
\text { point K }\end{array}$ & $\begin{array}{l}\text { Flow } \\
\text { point K }\end{array}$ & $\begin{array}{l}\text { Viscosity at 1573 K } \\
\text { (in poise) }\end{array}$ \\
\hline A & 1293 & 1363 & 1403 & 1.4 \\
\hline B & 1293 & 1398 & 1503 & 2.6 \\
\hline C & 1373 & 1423 & 1498 & 2.2 \\
\hline D & 1273 & 1373 & 1393 & 1.2 \\
\hline E & 1263 & 1348 & 1433 & 2.5 \\
\hline
\end{tabular}

Table 1(b). Chemical composition of test mould powders.

\begin{tabular}{|l|l|l|l|l|l|}
\hline Constituents & \multicolumn{5}{|c|}{ Types of Powder } \\
\hline & A & B & C & D & E \\
\hline $\mathrm{CaO}$ & 36.0 & 32.3 & 34.8 & 28.0 & 28.0 \\
$\mathrm{SiO}_{2}$ & 29.4 & 31.5 & 30.3 & 33.0 & 33.5 \\
$\mathrm{MgO}$ & 2.4 & 2.3 & 0.4 & 1.5 & 1.6 \\
$\mathrm{Al}_{2} \mathrm{O}_{3}$ & 5.4 & 5.5 & 7.0 & 5.0 & 4.8 \\
$\mathrm{Fe}_{2} \mathrm{O}_{3}$ & 1.5 & 2.7 & 0.2 & 2.2 & 1.3 \\
$\mathrm{Na}_{2} \mathrm{O}+\mathrm{K}_{2} \mathrm{O}$ & 3.30 & 2.7 & 7.5 & 13.0 & 10.5 \\
$\mathrm{~F}$ & 8.5 & 7.0 & 7.6 & 8.7 & 8.7 \\
Total Carbon & 8.3 & 7.5 & 4.4 & 6.0 & 5.9 \\
\hline
\end{tabular}

oscillator rod and was partly immersed in liquid steel bath. A fixed quantity of powder was placed inside the annular refractory ring and allowed to melt for $7 \mathrm{~min}$ at a temperature of $1773 \mathrm{~K}$. The thickness of the molten slag pool was measured by micro wire technique. ${ }^{2)}$

Apart from melting rate experiments, physical properties of the powders were also measured. The viscosity of the mould powders at $1573 \mathrm{~K}$ was measured using Brokefield Viscometer. The melting and flow points of the powders were measured using Leybold Heraus high temperature microscope. Slag pool thickness for different powders in actual casters were determined using micro wire technique. ${ }^{2)}$ The technique involves immersion of steel and copper wires $(\sim 1.5 \mathrm{~mm}$ dia.) into the mould using suitable fixture for about $5 \mathrm{sec}$. The difference in length of the wires after immersion indicates slag pool thickness.

The tests mentioned above was carried out using five types of mould powder and with variations of free carbon (graphite) in the range of 1-8\%. The powders tested along with their basic properties and chemical compositions is given in Tables 1(a) and 1(b).

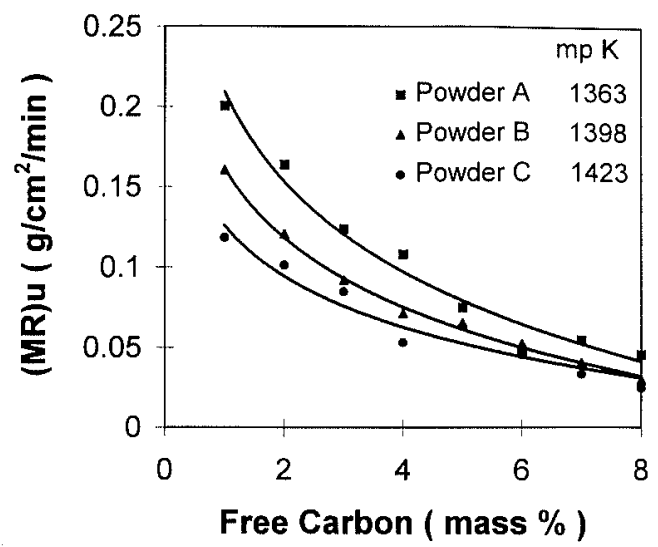

Fig. 4. Effect of free carbon and melting point on melting rate under one directional heating.

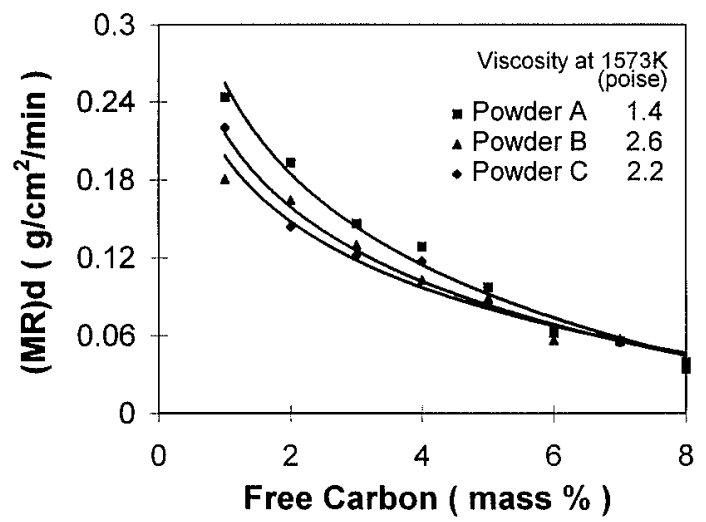

Fig. 5. Effect of free carbon and viscosity on melting rate under slag draining condition.

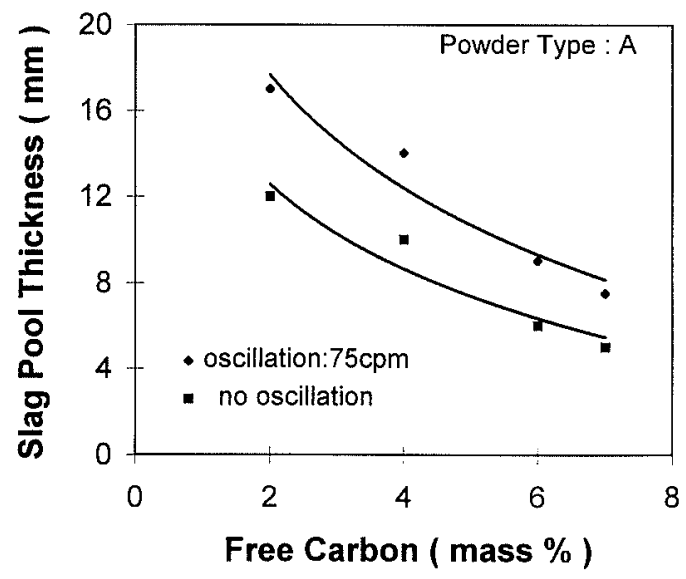

Fig. 6. Effect of oscillation on powder melting.

\section{Results and Discussion}

\subsection{Melting Characteristics under Different Test Con- dition}

Melting rate data under different application conditions i.e. one directional heating (MR $)_{\mathrm{u}}$, one directional heating with slag drainage $(\mathrm{MR})_{\mathrm{d}}$ and melting under oscillation are shown in Figs. 4, 5 and 6, respectively. The important observation were:

- Melting rate decreases with increase in free carbon content.

- Melting rate increased with decrease in melting point of the powder. The effect is particularly prominent 
when free carbon was low. This indicated major role of free carbon in controlling melt rate. (Fig. 4)

- Drainage of slag was more with decreasing viscosity. (Fig. 5)

- Mould oscillation facilitated powder melting; powder melting increased with increased frequency. (Fig. 6)

\subsection{Coefficients for Melt Rate Acceleration}

The results of melting rate tests presented in previous section show enhancement of melting rate on account of drainage (akin to slag infiltration into mould strand gap in continuous casting) and oscillation frequency. The experimental data show that effect of slag drainage and oscillation as melting rate accelerator can be conveniently represented through ratio-based coefficients i.e.

$$
\text { Drainage coefficient }(\alpha)=\frac{(M R)_{d}}{(M R)_{u}}
$$

$$
\begin{aligned}
& \text { Oscillation Coefficient }(\beta)= \\
& \text { Pool thickness with oscillation } \\
& \text { Pool thickness without oscillation }
\end{aligned}
$$

Keeping in view the dependence of $(M R)_{d}$ on free carbon, viscosity and flow point of the powder, drainage coefficient was correlated with these parameters. No correlation could be obtained when entire free carbon range (1-7\%) was considered. But quite good correlation could be achieved when the free carbon range was divided into two categories as shown below:

i) Free carbon from $1.0-4.0 \%$

$$
\begin{gathered}
\mathrm{MR}_{\mathrm{d}} / \mathrm{MR}_{\mathrm{u}}(\text { i.e. } \alpha)=0.01448 \cdot \text { Flow point }(\mathrm{K}) \\
-1.123 \cdot \eta \text { (poise) }-17.55 \\
R^{2}=0.97
\end{gathered}
$$

ii) Free carbon from $>4.0-7.0 \%$

$$
\begin{aligned}
& \left.\mathrm{MR}_{\mathrm{d}} / \mathrm{MR}_{\mathrm{u}} \text { (i.e. } \alpha\right)=0.00495 \cdot \text { Flow point }(\mathrm{K}) \\
& -0.062 \cdot \eta \text { (poise) }-5.70 \\
& R^{2}=0.90
\end{aligned}
$$

Applicability of separate correlation for different carbon range is only but expected from the nature of dependence of melting rate on carbon. In the case of $(\mathrm{MR})_{\mathrm{u}}$, which was extensively studied in the present work, it was seen that effect of melting point on melting rate changes significantly with free carbon. At very high carbon, it was seen to have marginal effect only.

The effect of oscillation coefficient (i.e. $\beta$ ) on free carbon, melting point and frequency of oscillation is shown in Figs. 7 and $\mathbf{8}$. The figures show only significant effect of frequency of oscillation and marginal to nil effect of free carbon and melting point. Marginalisation of effect of free carbon and melting point on oscillation coefficient is evident from the definition of the coefficient itself. The coefficient is determined from the ratio of melting rate tests under identical condition but for oscillation parameter, i.e. frequency of oscillation.

\subsection{Prediction of Mould Slag Thickness}

The melting rate enhancement factors, as above, have been fashioned to design an effective melting rate parameter (EMR) which accounts for casting conditions

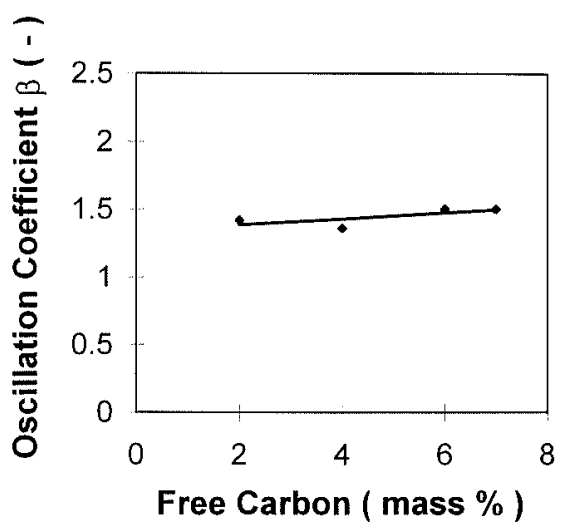

Fig. 7. Effect of free carbon in mould powder on oscillation coefficient

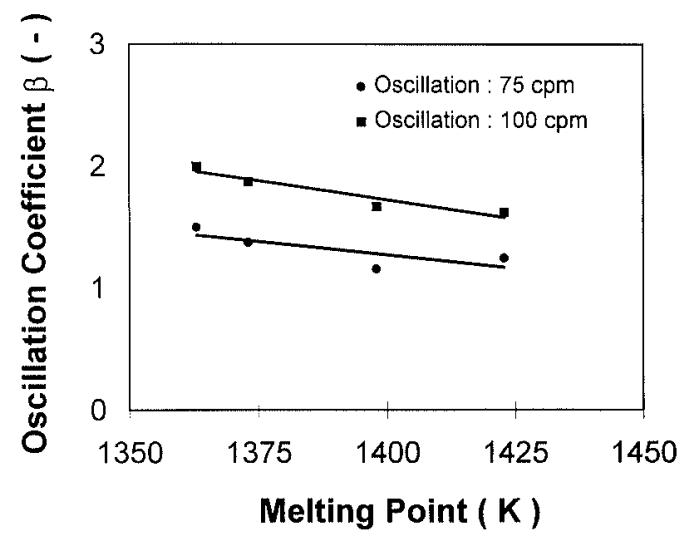

Fig. 8. Effect of melting point and frequency on oscillation coefficient

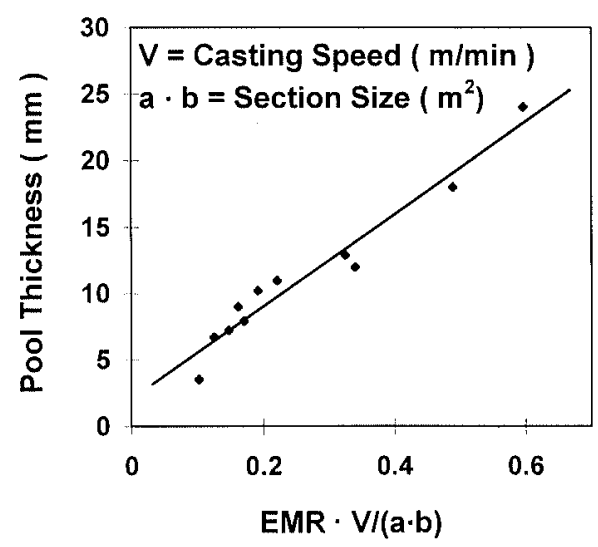

Fig. 9. Relationship of effective melting rate parameter (EMR) with slag pool thickness.

e.g. slag drainage and mould oscillation.

$$
\mathrm{EMR}=(\mathrm{MR})_{\mathrm{u}} \cdot \alpha \cdot \beta
$$

The applicability of the parameter EMR is shown in Fig. 9. In this figure, measured slag pool thickness for several powders in use in different slab casters has been plotted against corresponding $\operatorname{EMR} \cdot V /(a \cdot b)$ values in accordance with Eq. (2). The EMR values for the powders were generated through laboratory measurement of $(\mathrm{MR})_{\mathrm{u}}$, i.e. melting rate under one directional heating, experimentally determined $\beta$, use of $\alpha$ as given in Eqs. (5) and (6), caster operating data in regard to section size $(a \cdot b)$, casting speed $(\eta)$. The pool thickness 
Table 2. Caster operating data.

\begin{tabular}{|c|c|c|c|c|}
\hline $\begin{array}{l}\text { Powder } \\
\text { type }\end{array}$ & $\begin{array}{l}\text { Caster section } \\
\text { size } \mathbf{m m} \times \mathbf{~ m m}\end{array}$ & $\begin{array}{l}\text { Speed range } \\
\mathbf{m} . / \mathbf{m i n} .\end{array}$ & $\begin{array}{l}\text { Frequency of } \\
\text { oscillation } \mathbf{( c p m )}\end{array}$ & $\begin{array}{l}\text { Range of slag pool } \\
\text { thickness }(\mathbf{m m})\end{array}$ \\
\hline A & $1500 \times 250$ & $0.55-0.80$ & 75 & $9-12$ \\
\hline B & $1500 \times 250$ & $0.55-0.75$ & 75 & $3-8$ \\
\hline C & $1285 \times 170$ & 0.80 & 75 & 13 \\
\hline D & $1040 \times 210$ & $0.65-0.85$ & $56-80$ & $9-12$ \\
\hline E & $1500 \times 200$ & $0.90-1.50$ & $64-120$ & $12-23$ \\
\hline
\end{tabular}

data and the allied caster operating data are given in Table 2. The data plotted (Fig. 9) show excellent correlation of ' $d$ ' $v s$. (EMR $V / a b)$. The correlation equation translates to:

$$
\begin{gathered}
d=35.70 \cdot \mathrm{EMR} \cdot V /(a \cdot b)+2.1 \\
R^{2}=0.94
\end{gathered}
$$

Where, $\quad d=$ Slag pool thickness ( $\mathrm{mm}$ )

$\mathrm{EMR}=$ Effective melting rate parameter $\left(\mathrm{g} / \mathrm{cm}^{2}\right)$ min)

$V=$ Casting speed $(\mathrm{m} / \mathrm{min})$

$a \cdot b=$ Section size $\left(\mathrm{m}^{2}\right)$

$R=$ Regression coefficient

The high confidence level of the correlation (i.e. Eq. (8)) indicate the feasibility of the equation for predictive purposes. Such prediction will require laboratory measurement of (MR) $)_{\mathrm{u}}$, experimental determination of $\beta$, utilisation of $\alpha$ as in Eqs. (5) and (6) or laboratory determination of $\alpha$ through measurement of $(\mathrm{MR})_{\mathrm{d}}$ / $(\mathrm{MR})_{\mathrm{u}}$ and utilisation of Eq. (8). The method developed is clearly independent of any type of plant measurement.

The plant data shown in Fig. 9 pertains to casting speed range of 0.55 to $1.5 \mathrm{~m} / \mathrm{min}$. Accordingly, the Eq. (8) is applicable for the same speed range. The powder characteristics utilized in formulating Eqs. (5) and (6) is given in Tables 1(a) and 1(b). These also conform to the general specifications recommended for slab casting in the speed range of 0.55 to $1.5 \mathrm{~m} / \mathrm{min} .{ }^{19)}$

It, however, may be noted that laboratory determination of $(\mathrm{MR})_{\mathrm{u}}$ and $(\mathrm{MR})_{\mathrm{d}}$ are fairly straight forward but determination of $\beta$ (i.e. oscillation coefficient) requires complex experimentation. Further work is necessary to simplify generation of this coefficient.

\section{Conclusion}

The melting behavior of mould powder leading to formation of mould slag during continuous casting of steel has been rationalised. It has been shown that slag pool thickness correlates well with melting property of powder, modified to take into account the acceleration effect of slag drainage (i.e. consumption) and mould oscillation. The correlation developed is valid upto casting speed of $1.5 \mathrm{~m} / \mathrm{min}$.

A method has been proposed for utilisation of the correlation for predicting molten slag pool thickness in actual casting entirely based on laboratory measurements.

\section{REFERENCES}

1) T. Nakano, T. Kishi, K. Koyama, T. Komai and S. Naitoh: Trans. Iron Sieel Inst. Jpn., 24 (1984), 950.

2) S. Ogibayashi, T. Mukai, Y. Mimura, Y. Nagano, K. Yamaguchi, T. Takahashi, K. Koyama and T. Nakano: Nippon Sieel Tech. Rep., 34 (1987), 1.

3) H. Nakato, S. Takeuchi, T. Fujii, T. Nozaki and M. Washio: Proc. Steelmaking Conf., 74 (1991), 639.

4) R. Bommaraju: Proc. Steelmaking Conf., 74 (1991), 131.

5) J. A. Moore, R. J. Phillips and T. C. Gibbs: Proc. Steelmaking Conf., 74 (1991), 615.

6) K. C. Mills: Proc. Steelmaking Conf., 74 (1991), 121.

7) T. Emi, H. Nakato, Y. Iida, K. Emoto, R. Tachibana, T. Imai and $H$. Bada: Proc. Open Hearth and Basic Oxygen Conf., 61 (1978), 350)

8) P. H. Dauby, W. H. Emling and R. Sobolewski: Iron Steelmaker, 13 (1986), No. 2, 28.

9) Robert V. Branion: Mold Powders for Continuous Casting and Bottom Pour Tecming, ed. by G. Harry, ISS AIME, Warrendale. PA. (1987), 3.

10) RDCIS: SAIL Intenal Report No:: RD: 26:02:2456: $01: 96$ (1995).

11) H. Nakato, S. Takeuchi, T. Fujii, T. Nozaki and M. Washio: Proc. Steelmaking Conf., 74 (1991), 639.

12) M. Kawamoto, K. Nakajima, T. Kanazawa and K. Nakai: Proc. Steelmaking Conf., 75 (1992), 389.

13) K. Koyama. Y. Nagano, K. Nagano and T. Nakano: Nippon Sleel Tech. Rep., 34 (1987), 41

14) T. Nakano, K. Nagano, N. Masuo, M. Fuji and T. Matsuyama: Nippon Sieel Tech. Rep., 34 (1987), 21.

15) B. Xie, J. Wu and Y. Gan: Proc. Steelmaking Conf., 74 (1991), 647.

16) K. C. Mills, P. Grieveson, P. V. Ribound and K. Schwerdtfeger: Report EUR 9560, ECSC Contract 7210 C/131/311/810,(1985).

17) M. B. Coldschmil, J. C. Gonzalez and E. N. Dvorkin: Ironmaking Steednaking, 20 (1993), No. 5, 379.

18) A. Delhalle, M. Larreeq, J. F. Marioton and P. V. Ribound: Mold Powders for Continuous Casting and Bottom Pour Teeming, ed. by G. Harry, ISS AIME, Warrendale, PA, (1987), 14.

19) M. N. Wolf: METEC Cong. 942 nd Europeun Continuous Casting Conf. Dusseldrof, (1994), 78 